\title{
Silver Nanoparticles Catalyzed Synthesis and Antimicrobial Activity of 2-Amino-4H-Chromenes
}

\author{
Priya Khandare ${ }^{1}$, Rajiv Dixit ${ }^{2}$, Sadhna Salve ${ }^{1}$, Sunil Tekale ${ }^{1}$, Rajita Ingle ${ }^{1, *}$, Rajendra Pawar ${ }^{1, *}$ \\ Department of Chemistry, Deogiri College, Station Road, Aurangabad - 431005 (Maharashtra) India \\ Kuvempu University, Shimoga, Karnataka-577451, India \\ * Correspondence: rajitaingle@yahoo.in (R.I.), rppawar@yahoo.com (R.P.);
}

Scopus Author ID 7003738785

Received: 22.01.2021; Revised: 28.03.2021; Accepted: 2.04.2021; Published: 8.05.2021

Abstract: A simple and one-pot protocol has been developed to synthesize bioactive 2-amino- $4 \mathrm{H}$ chromenes by using silver nanoparticles $(\mathrm{AgNp})$ as a catalyst at room temperature in an aqueous medium. This method provides operational simplicity and an environment-friendly green approach. All the synthesized compounds were evaluated for antifungal activity against Alternaria alternata.

Keywords: silver nanoparticles; chromenes; antifungal.

(C) 2021 by the authors. This article is an open-access article distributed under the terms and conditions of the Creative Commons Attribution (CC BY) license (https://creativecommons.org/licenses/by/4.0/).

\section{Introduction}

2-Amino- $4 H$ chromenes are an influential class of heterocyclic compounds [1], present in plants, including edible vegetables and fruits [2]. They show various biological and pharmacological activities such as antibacterial [3], anti-tubercular [4], anticancer [5], etc. Literature survey reveals that various methods have been developed to synthesize chromene derivatives by using PEG-400 [6], silica gel supported polyamine [7], etc. Many bacterial and fungal species have antimicrobial activity by reducing the metal ions to produce metal nanoparticles. Recent studies showed that fungi possess a good potential for synthesizing bioactive compounds compared with bacteria [8].

The application of $\mathrm{AgNp}$ as a catalyst in organic transformations was found to be of increasing interest due to the high effectiveness of acting as a suitable Lewis acid in organic synthesis. Nanoparticles and composites have attracted the scientific community's attention due to their wide range of applications [9]. In continuation of our previous work [10-11], herein we report a one-pot three-component synthesis of chromene derivatives by the reaction of aromatic aldehydes, malononitrile, resorcinol, and $\mathrm{AgNp}$ catalyst in an aqueous medium at room temperature in a short reaction time.

\section{Materials and Methods}

All reagents and chemicals were of analytical grade and used without further purification. Melting points were determined in capillaries open at one end and were uncorrected. 


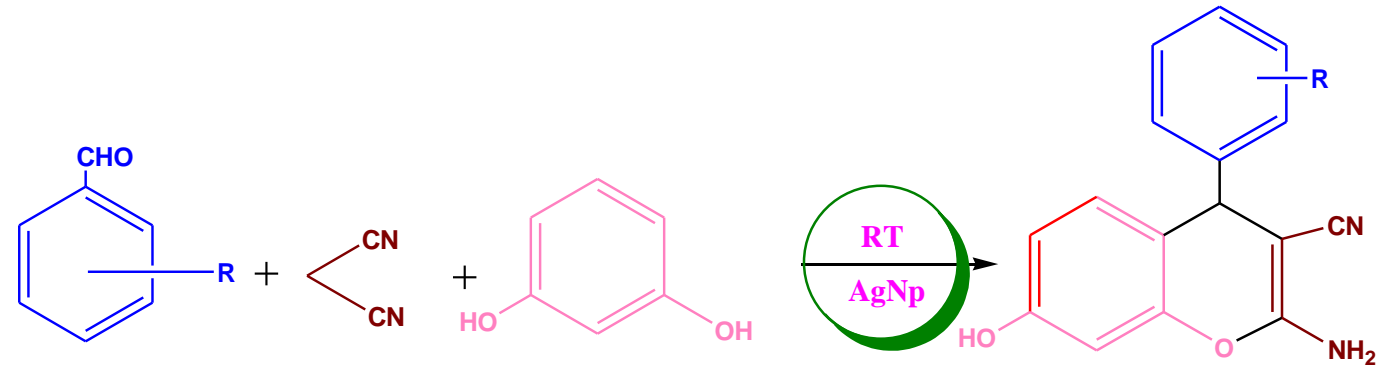

Scheme 1. Synthesis of 2-amino- $4 H$-chromenes using AgNp as a catalyst.

\subsection{General procedure for the synthesis of 2-amino-4H-chromene derivatives.}

In a $25 \mathrm{~mL}$ round bottom flask, substituted benzaldehyde $(1 \mathrm{mmol})$, malononitrile (1 $\mathrm{mmol})$, resorcinol $(1 \mathrm{mmol})$, and $\mathrm{AgNp}(0.07 \mathrm{mmol})$ were taken in $5 \mathrm{~mL}$ water as a green solvent. The resulting reaction mixture was stirred at room temperature, as indicated in Table 1. Thin Layer Chromatography (TLC) monitored the progress of reaction using $30 \%$ ethyl acetate: $\mathrm{n}$-hexane as the mobile phase. After completing the reaction, the solid product obtained was filtered off along with the catalyst and washed with water. The mixture containing crude product and the catalyst was diluted with hot ethanol and filtered off to separate residue as the recovered catalyst. The filtrate was concentrated on a rotary evaporator and finally recrystallized with hot ethanol to afford the pure product. All the synthesized compounds were confirmed by comparing their melting points with the reported values, IR and ${ }^{1} \mathrm{H}$ NMR data.

\section{Results and Discussion}

The reaction conditions were optimized on the model reaction of 2- $\mathrm{NO}_{2}$-benzaldehyde, malononitrile, resorcinol, and $\mathrm{AgNp}$ as a catalyst by using various solvents such as water, ethanol, and dimethyl sulfoxide (DMSO) as solvents at room temperature. The results obtained are presented in Table 2. A high yield of products was obtained with $94 \%$ yield in 10 minutes at room temperature.

To understand the amount of catalyst to obtain maximum yield, we have carried out the model reaction with different amounts of catalyst (Table 3) and found that $0.07 \mathrm{mmol}$ of the catalyst was sufficient. Further increase in the amount of catalyst does not affect the yield of the desired product significantly.

Table 1. Synthesis of 2-amino-4H-chromene derivatives.

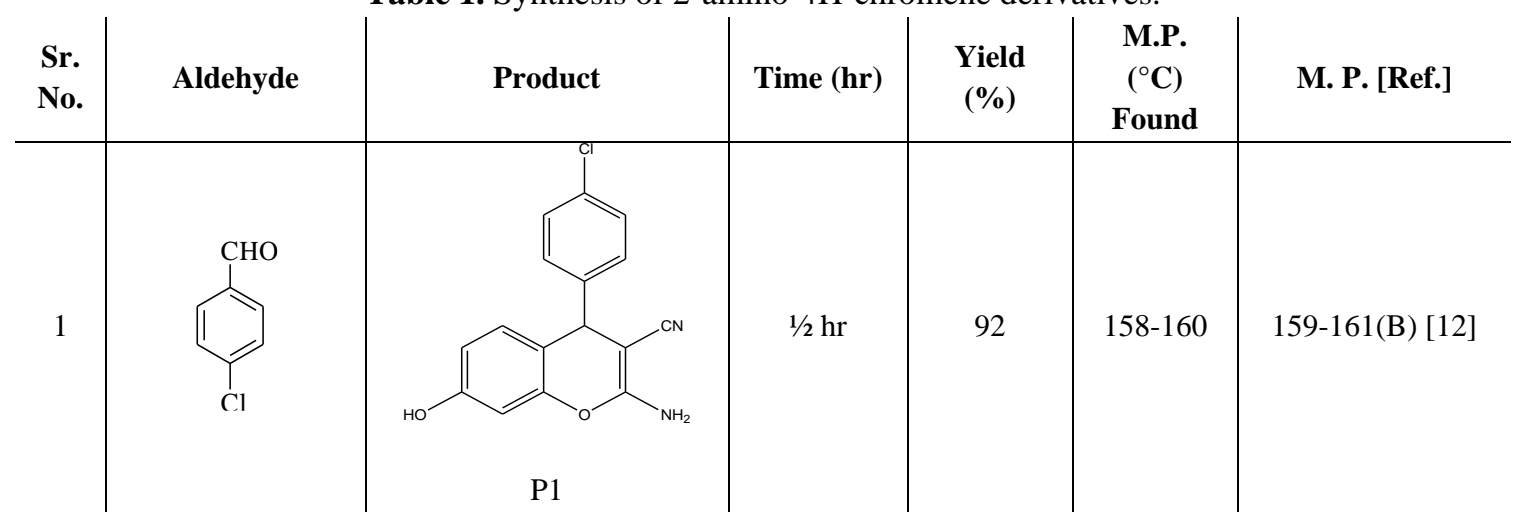




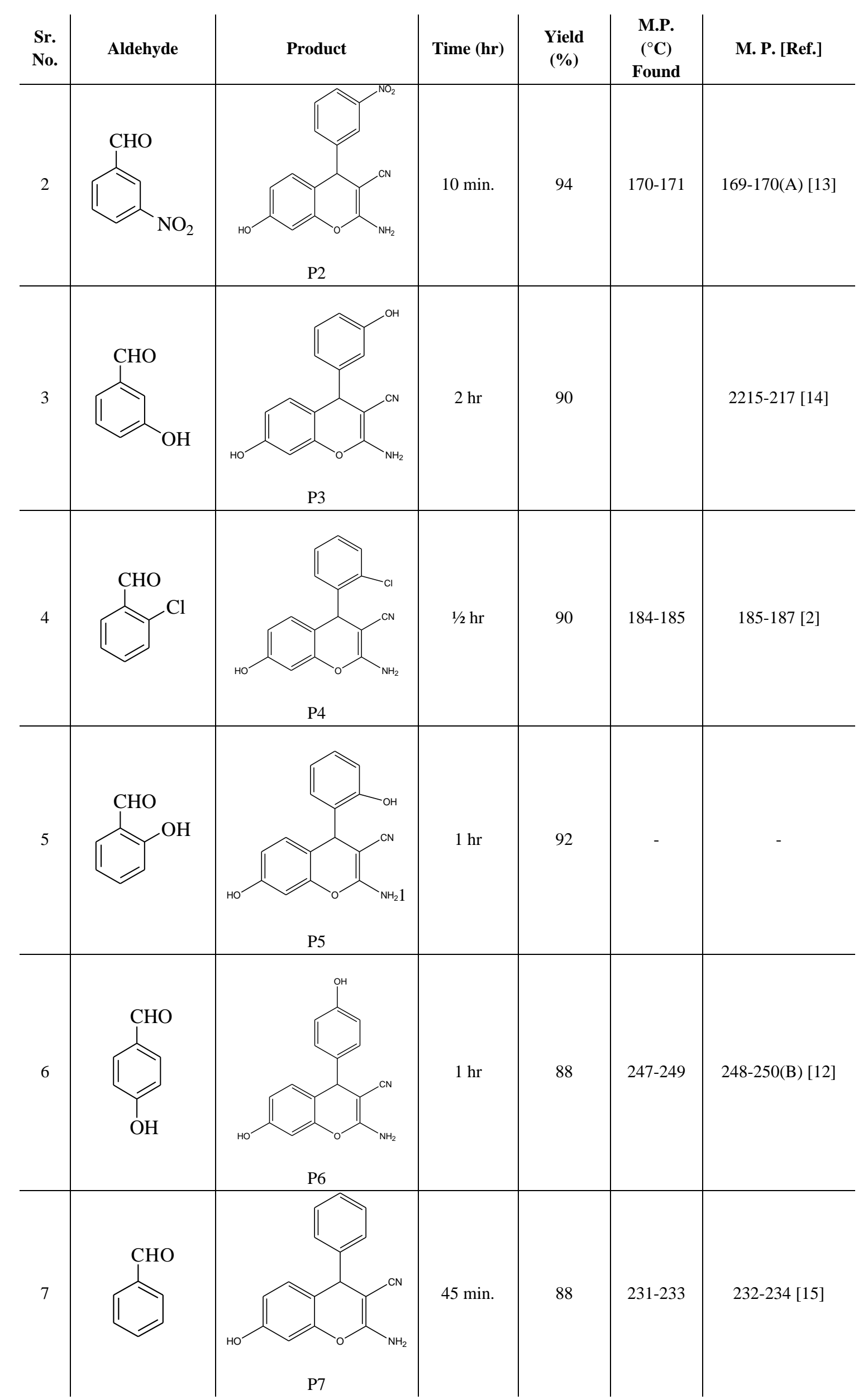




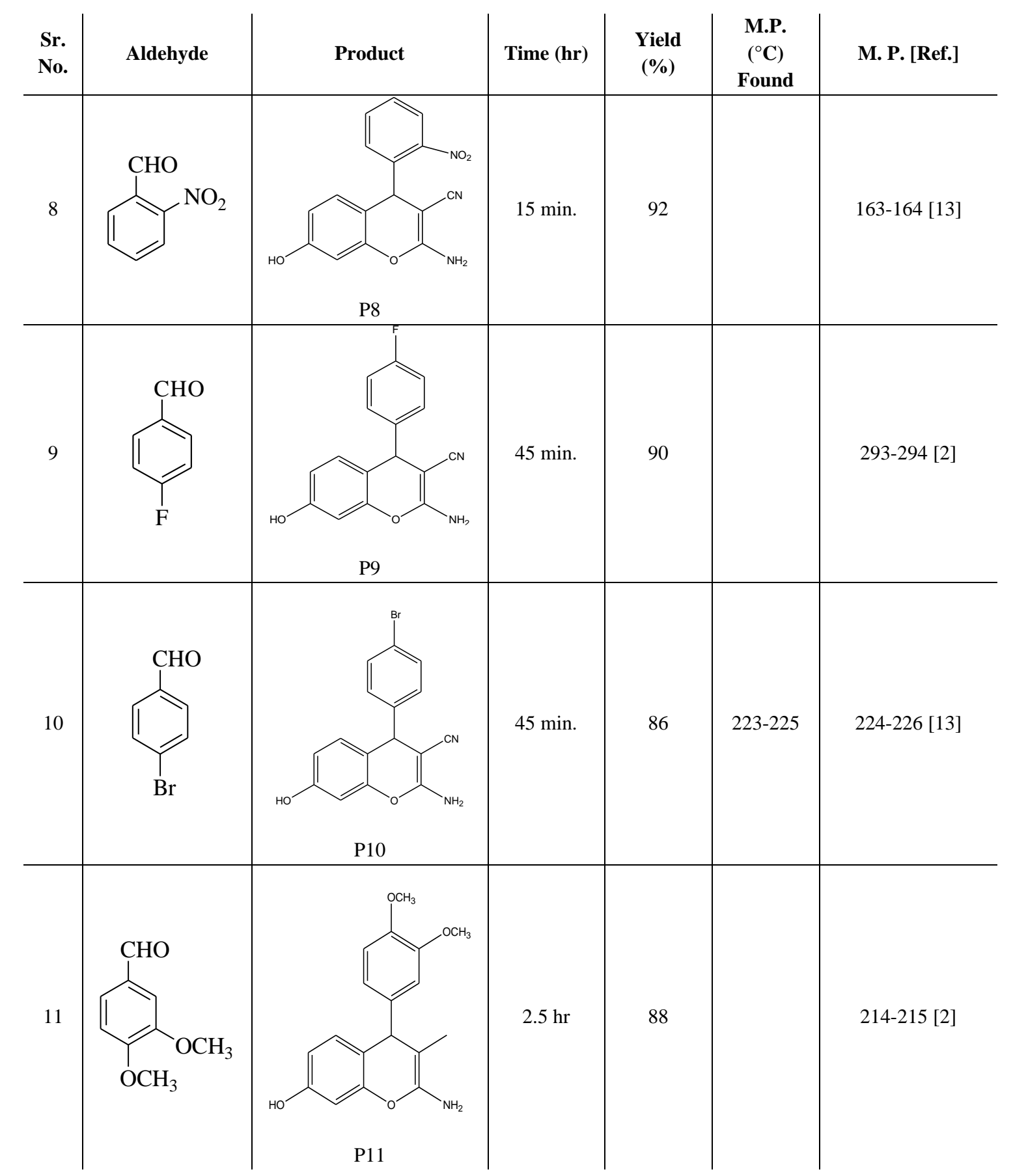

Table 2. Effect of different solvents on the synthesis of 2-amino-4H-chromene derivatives.

\begin{tabular}{l|l|l|l} 
Entry & Solvent & Time $(\mathbf{m i n})$ & Yield $(\%)$ \\
\hline 1 & $\mathrm{H}_{2} \mathrm{O}$ & 10 & 95 \\
\hline 2 & $\mathrm{EtOH}$ & 45 & 86 \\
\hline 3 & $\mathrm{DMSO}$ & 7200 & $<20$
\end{tabular}

Table 3. Effect of catalyst concentration on the synthesis of 2-amino-4H-chromene derivatives.

\begin{tabular}{l|l|l} 
Entry & Amount of catalyst $(\mathbf{m m o l})$ & Yield $(\%)$ \\
\hline 1 & 0.1 & 70 \\
\hline 2 & 0.2 & 60 \\
\hline 3 & 0.4 & 30 \\
\hline 4 & 0.7 & 94
\end{tabular}

\subsection{Mechanism.}

A plausible reaction mechanism is outlined below in Scheme 2: 
Firstly, aldehyde (1) was activated by AgNp to generate 2-arylidenemalononitrile (3), which was formed by the condensation reaction of an activated aldehyde with malononitrile (2). 2-Arylidenemalononitrile, after activation with $\mathrm{AgNp}$, underwent nucleophilic attack by resorcinol (4) to form active intermediates (5), which simultaneously aromatized (6), activated, and underwent cyclization (7) to form the final product (7), and $\mathrm{AgNp}$ was recovered from the reaction mixture.

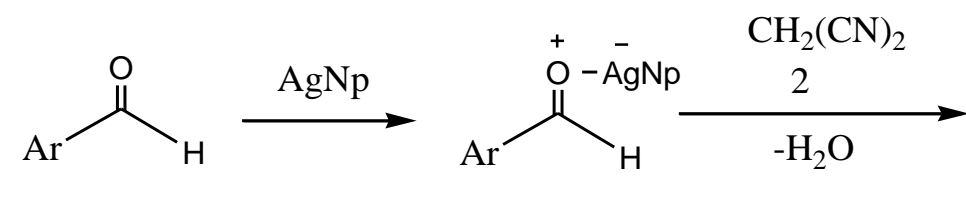<smiles>N#CC=C(C#N)C#N</smiles>

$-\mathrm{AgNP}$

$\mathrm{AgNp}$<smiles>CC(C(=N)C1C=CC(O)=CC1O)C(=O)C#N</smiles>

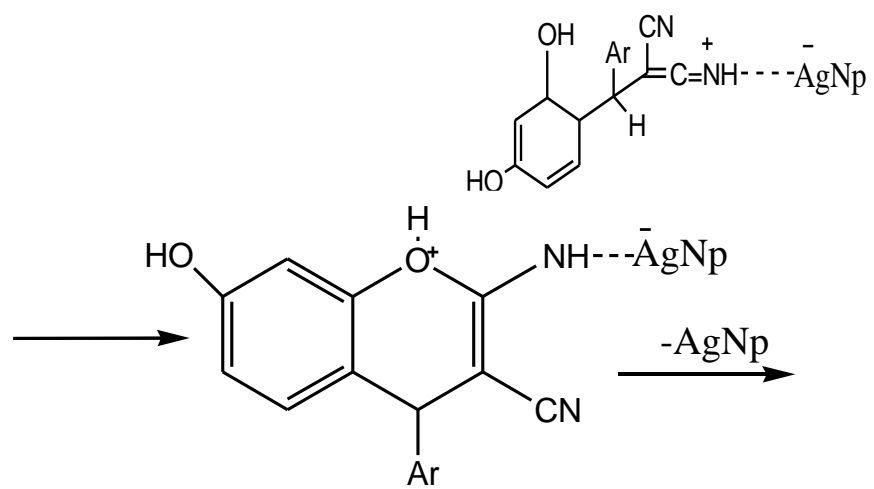

7<smiles>N#CC1=C(N)Oc2cc(O)ccc2C1Br</smiles>

8

Scheme 2. Plausible mechanism for the synthesis 2-amino- $4 H$-chromenes catalyzed by Ag-nanoparticles.

\subsection{Spectral data of synthesized compounds.}

2-Amino-7-hydroxy-4-(2-nitrophenyl)-4H-chromene-3-carbonitrile: ${ }^{1} \mathrm{H}$ NMR: (400 MHz, DMSO-d d $_{\text {) }} \delta$ ppm 2.27 (s, 2H), $4.12(\mathrm{~s}, 1 \mathrm{H}), 6.65-6.79(\mathrm{~m}, 1 \mathrm{H}), 6.79-6.93(\mathrm{~m}, 3 \mathrm{H}), 6.97$ (s, 1H), 7.05 (d, 2H, J = 8.8 Hz); ${ }^{13} \mathrm{C}$ NMR (100 MHz, DMSO-d6) 40.76, 111.72, 119.26, $120.85,123.29,124.29,124.27,130.74,132.51,133.71,135.10,139.00,143.59,148.39$, 149.08; IR (KBr) cm $\mathrm{cm}^{-1}: 3735.73\left(\mathrm{NH}_{2}\right), 3652.81(-\mathrm{OH}), 3040.00(\mathrm{C}-\mathrm{H}), 2226.71(-\mathrm{CN})$, $1693.88(\mathrm{C}=\mathrm{C}), 1509.64(\mathrm{Ar}-\mathrm{C}=\mathrm{C}), 1147.80(\mathrm{C}-\mathrm{N})$; HRMS (309.13). 
Table 4. Antifungal activity of the synthesized compounds (1-6, 9, 10, 11, 12).

\begin{tabular}{c|c} 
Compounds & $\begin{array}{c}\text { Zone of inhibition in mm } \\
\text { against Alternaria alternate }\end{array}$ \\
\hline $\mathrm{P}_{1}$ & 12 \\
$\mathrm{P}_{2}$ & 20 \\
$\mathrm{P}_{3}$ & 25 \\
$\mathrm{P}_{4}$ & 20 \\
$\mathrm{P}_{5}$ & 20 \\
$\mathrm{P}_{6}$ & 29 \\
$\mathrm{P}_{7}$ & 25 \\
$\mathrm{P}_{8}$ & 28 \\
$\mathrm{P}_{9}$ & 20 \\
$\mathrm{P}_{10}$ & 19 \\
$\mathrm{P}_{11}$ & 23 \\
Standard & 02
\end{tabular}

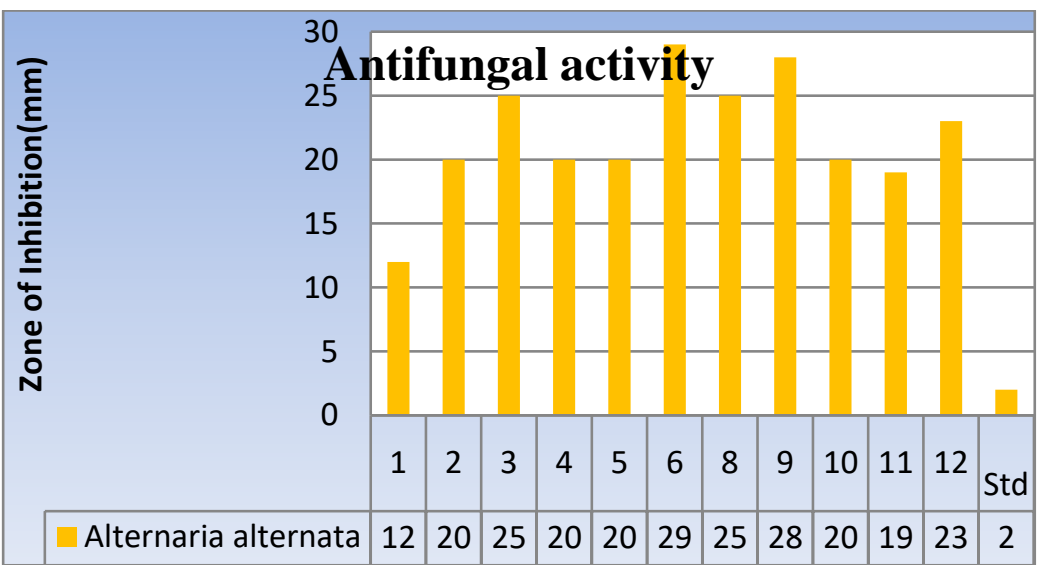

Figure 1. Antifungal activity of the synthesized compounds.

\subsection{Antifungal activity.}

Antifungal activity of the synthesized compounds was screened against the fungal species Alternaria alternata using the agar well disc diffusion method. Observations were recorded after $72 \mathrm{hr}$, and the zones of inhibition were measured in millimeters. Carbendazim was used as the standard. It was observed that all the synthesized compounds showed antifungal activity against Alternaria alternata. All compounds showed moderate to good antifungal activity as compared to the standard Carbendazim.

\section{Conclusions}

In conclusion, herein we report the synthesis of 2-amino- $4 H$-chromene derivatives by one-pot multicomponent protocol using an aqueous medium at room temperature. This method's advantages are short reaction time, easy workup procedure, water as a solvent, and a high atom economy. All the synthesized derivatives of chromenes showed good antifungal activity at low concentrations.

\section{Funding}

This research received no external funding. 


\section{Acknowledgments}

We are thankful to the Principal, Deogiri College, Aurangabad, for providing the necessary laboratory facilities.

\section{Conflicts of Interest}

The authors declare no conflict of interest.

\section{References}

1. Pagore, V.P.; Tekale, S.U.; Rupnar, B.D.; Pawar, R.P. Efficient and green synthesis of 2-amino-4Hchromenes. Journal of Chemical and Pharmaceutical Research. JCHPS 2015, 7, 1057-1061.

2. Kidwai, M.; Saxena, S.; Rahman Khan, M.K.; Thukral, S.S. Aqua mediated synthesis of substituted 2-amino4H-chromenes and in vitro study as antibacterial agents. Bioorg. Med. Chem. Lett. 2005, 15, 4295-4298, https://doi.org/10.1016/j.bmcl.2005.06.041.

3. Kantharaju, K.; Khatavi, S.Y. A green method synthesis and antimicrobial activity of 2-amino-4H-chromene derivatives. Asian Journal of Chemistry 2018, 30, 1496-1502. https://doi.org/10.14233/ajchem.2018.21191.

4. Kamdar, N.R.; Haveliwala, D.D.; Mistry, P.T.; Patel, S.K. Synthesis and evaluation of in vitro anti-tubercular activity and antimicrobial activity of some novel $4 \mathrm{H}$-chromeno[2,3-d]pyrimidine via 2-amino-4-phenyl-4Hchromene-3-carbonitriles. Med. Chem. Res. 2011, 20, 854-864, https://doi.org/10.1007/s00044-010-9399-x.

5. Kemnitzer, W.; Jiang, S.; Wang, Y.; Kasibhatla, S.; Crogan-Grundy, C.; Bubenik, M.; Labrecque, D.; Denis, R.; Lamothe, S.; Attardo, G.; Gourdeau, H.; Tseng, B.; Drewe, J.; Cai, S.X. Discovery of 4-aryl-4Hchromenes as a new series of apoptosis inducers using a cell- and caspase-based HTS assay. Part 5: Modifications of the 2- and 3-positions. Bioorg. Med. Chem. Lett. 2008, 18, 603-607, https://doi.org/10.1016/j.bmcl.2007.11.078.

6. Shitole, N.V.; Shelke, K.F.; Sadaphal, S.A.; Shingate, B.B.; Shingare, M.S. PEG-400 remarkably efficient and recyclable media for one-pot synthesis of various 2-amino-4H-chromenes. Green Chemistry Letters and Reviews 2010, 3, 83-87, https://doi.org/10.1080/17518250903567246.

7. Magar, R.L.; Thorat, P.B.; Jadhav, V.B.; Tekale, S.U.; Dake, S.A.; Patil, B.R.; Pawar, R.P. Silica gel supported polyamine: A versatile catalyst for one pot synthesis of 2-amino-4H-chromene derivatives. J. Mol. Catal. A: Chem. 2013, 374-375, 118-124, https://doi.org/10.1016/j.molcata.2013.03.022.

8. Kalyani, P.; Vineela, K.C.; Geetha, S.; Hemalatha, K.P.J. Green synthesis of silver nano particles from Aspergillus niger (MTCC-961). Int. J. Curr. Microbiol. App. Sci 2016, 5, 50-56, https://doi.org/10.20546/ijcmas.2016.510.007.

9. Mukhopadhyay, O.; Dhole, S.; Mandal, B.K.; Khan, F.R.N.; Ling, Y.C. Synthesis, characterization and photocatalytic activity of $\mathrm{Zn}^{2+}, \mathrm{Mn}^{2+}$ and $\mathrm{Co}^{2+}$ doped $\mathrm{SnO}_{2}$ nanoparticles. Biointerface Research in Applied Chemistry 2019, 9, 4199-4204, https://doi.org/10.33263/BRIAC95.199204.

10. Kendrekar, P; Mashele, S.; Tekale, S.; Pawar, R. Synthesis of some novel and potent anti-plasmodial aminoalkyl chalcone derivatives. Biointerface Research in Applied Chemistry 2020, 10, 6076-6081, https://doi.org/10.33263/BRIAC105.60766081

11. Gore, V.A.; Tekale, S.U.; Bhale, S.P.; Rajani, D.P.; Domb, A.J.; Pawar, R.P. Synthesis and biological evaluation of novel thiazole hydrazines as antimicrobial and antimalarial agents. Letters in Applied NanoBioScience 2021, 10, 1846-1855, https://doi.org/10.33263/LIANBS101.18461855

12. Khaksar, S.; Rouhollahpour, A.; Talesh, S.M. A facile and efficient synthesis of 2-amino-3-cyano-4Hchromenes and tetrahydrobenzo[b]pyrans using 2,2,2-trifluoroethanol as a metal-free and reusable medium. J. Fluorine Chem. 2012, 141, 11-15, https://doi.org/10.1016/j.jfluchem.2012.05.014.

13. Safari, J.; Heydarian, M.; Zarnegar, Z. Synthesis of 2-amino-7-hydroxy-4H-chromene derivatives under ultrasound irradiation: A rapid procedure without catalyst. Arabian Journal of Chemistry 2017, 10, S2994S3000, https://doi.org/10.1016/j.arabjc.2013.11.038.

14. Javanshir, S.; Safari, M.; Dekamin, M.G. A facile and green three-component synthesis of 2-amino-3-cyano7-hydroxy-4H-chromenes on grinding. Scientiairanica C 2014, 21, 742-747.

15. Safari, J.; Zarnegar, Z.; Heydarian, M. Practical, ecofriendly, and highly efficient synthesis of 2-amino-4Hchromenes using nanocrystalline $\mathrm{MgO}$ as a reusable heterogeneous catalyst in aqueous media. Journal of Taibah University for Science 2013, 7, 17-25. https://doi.org/10.1016/j.jtusci.2013.03.001. 